\title{
CONTRIBUIÇÕES DAS REDES SOCIAIS DA INTERNET PARA O ENSINO DE CIÊNCIAS
}

\author{
Contributions of Internet Social Networks for Science Teaching
}

\author{
Matheus Lincoln Borges dos Santos ${ }^{1}$ \\ Álvaro Emilio Leite ${ }^{2}$
}

\begin{abstract}
Resumo: Este trabalho apresenta a realização de uma revisão de literatura com o objetivo de levantar as contribuições das redes sociais da internet para o ensino de ciências no âmbito da educação básica. A busca dos trabalhos que compuseram esta revisão ocorreu em língua inglesa e portuguesa nas bases de dados Web of Science, Scopus e revistas classificadas nos parâmetros A1 e A2 do Qualis da CAPES na área de ensino. Foram analisados 25 artigos através da análise de conteúdo que tratavam da utilização das redes sociais no ensino de ciências na educação básica. A análise dos trabalhos identificou a existência de três grupos de trabalhos: formação de comunidades de aprendizado e aprendizado colaborativo através das redes sociais; relatos de contribuições das redes sociais para a prática docente e o impacto das redes sociais no processo de ensino e aprendizagem de ciências. Esses grupos acabam por convergir ao encontro do aprendizado cooperativo e o engajamento dos alunos, à necessidade da formação de professores frente às ferramentas audiovisuais e o desenvolvimento de novas habilidades e competências necessárias para a vida nos tempos atuais.
\end{abstract}

Palavras-chave: Redes sociais. Ensino de ciências. Aprendizado colaborativo.

Abstract: This work presents a literature review with the objective of surveying the contributions of social networks on the internet to the teaching of science in the scope of basic education. The search for the papers that compose this review occurred in English and Portuguese on Web of Science, Scopus and journals classified in parameters A1 and A2 of CAPES Qualis in the area of education. We analyzed 25 articles that dealt with the use of social networks in science teaching in basic education. The analysis identified three groups of works: formation of learning communities and collaborative learning through social networks; reports of social network contributions to teaching practice and the impact of social networks on the teaching and learning of science. These groups eventually converge on cooperative learning and student engagement, the need to train teachers to use audiovisual tools and the development of new skills and competences necessary for life in our times.

Keywords: Social networks. Science teaching. Collaborative learning.

\footnotetext{
1 Graduado em Física pela Universidade Federal do Paraná (UFPR) e em Engenharia Elétrica pela Pontifícia Universidade Católica do Paraná. Mestre em Ensino de Ciências e Matemática pela Universidade Tecnológica Federal do Paraná (UTFPR) e mestre em Engenharia de Produção pela UFPR. Atualmente é analista educacional da rede Marista Centro-Norte. Orcid: 0000-0003-3371-8994. E-mail: matheuslincoln@gmail.com.

${ }^{2}$ Graduado em Física, mestre e doutor em Educação pela UFPR. Atualmente é professor adjunto do departamento de Física da UTFPR e professor permanente do Programa de Pós-graduação em Formação Científica, Educacional e Tecnológica da UTFPR. Orcid: 0000-0001-8817-6630 E-mail: alvaroemilioleite@ gmail.com.
} 


\section{Introdução}

As redes sociais virtuais, tais como o Facebook, o Instagram, o Youtube, entre outras, vem modificando o nosso modo de nos relacionarmos com as pessoas, nos comunicarmos, adquirirmos informação e entretenimento etc. A proximidade cada vez maior do mundo on-line com o mundo off-line, ou a junção desses dois, trazida por essas plataformas, pode ser observada também na área da educação, trazendo implicações para o processo de ensino e aprendizagem. Estes espaços podem ser utilizados como um meio de interação entre o professor-aluno, aluno-conteúdo, professor-conteúdo e professor-aluno-conteúdo. Essas interações acabam por transformar a sala de aula, inclusive dos docentes que não utilizam tais recursos, uma vez que seus alunos podem buscar explicações alternativas ou ser expostos a tópicos do conteúdo aprendido nestes espaços.

O ensino de ciências, partindo de uma abordagem que inter-relacione ciências, tecnologia e sociedade é focado na resolução de problemas autênticos, na pesquisa e nas atividades experimentais, no trabalho colaborativo e na abordagem interdisciplinar de temas contemporâneos (CHAGAS, 2001). Nesta perspectiva, se revela a importância do ensinar a confrontar pontos de vista, analisar criticamente argumentos, discutir os limites de conclusões alcançadas e a formular novas questões (MARTINS, 2002). Sendo as redes sociais um espaço propício para o compartilhamento de notícias, informações e de conhecimento; de debate de pontos de vista; de formação de comunidades baseadas em interesses e de interação humana (RECUERO, 2009), se torna necessário investigar a potencialidade destes espaços virtuais de interação para o ensino de ciências.

Dentro da área de ensino de ciências, destacam-se linhas de pesquisa dedicadas ao estudo da relação entre as tecnologias da informação e comunicação e o processo de ensino e aprendizagem, área esta, de que este estudo faz parte. Compreender como as tecnologias podem mediar o processo de ensino e aprendizagem, é fundamental para a melhoria da educação e para a atualização da sala de aula aos novos contextos socioculturais (SANTOS et al. 2018).

Com o objetivo de responder a seguinte pergunta de pesquisa: "como as redes sociais podem contribuir para o ensino de ciências na educação básica?" Este trabalho efetuou uma revisão de literatura com o objetivo de construir uma síntese dos principais trabalhos relacionados a esta temática. O resultado desta revisão de literatura contribuirá para a área de ensino de ciências ao apontar os caminhos da produção acadêmica a respeito dos impactos e das possibilidades da utilização das redes sociais no ensino de ciências.

\section{Redes sociais da Internet}

Uma rede social é definida como um conjunto de dois elementos: atores e conexões. Os atores são as pessoas, instituições ou grupos (os nós da rede), enquanto as conexões representam interações ou laços sociais desses sujeitos (WASSERMAN; FAUST, 1994; DEGENNE; FORSE, 1999). A representação de uma rede de nós interconectados (Figura 1) é, então, uma metáfora para observar padrões de conexão de um grupo social e sua estrutura social, ou seja, uma ação que ocorre de maneira coletiva, em que o sujeito modifica e é modificado pelo grupo em que se está inserido (RECUERO, 2009). 
Figura 1 - Representação dos atores e suas conexões numa rede social

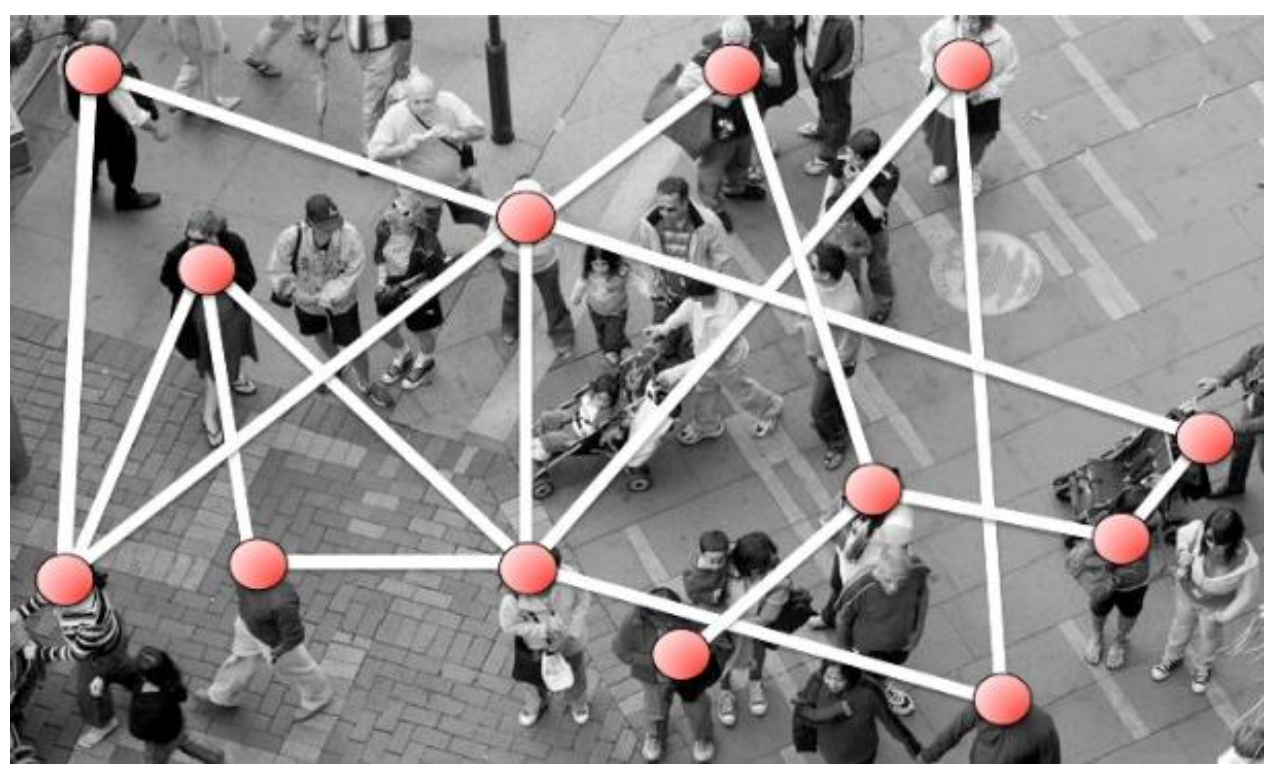

Fonte: Google Imagens (20180.

As redes sociais, ou os grupos sociais, podem ser observadas em toda a história, porém, com o advento da internet e a criação de sites e plataformas de socialização e agrupamento de pessoas, elas ganharam em escala, intensidade e frequência.

No contexto das redes sociais virtuais ou das redes sociais na internet, segundo Recuero (2009), os atores são o primeiro elemento de uma rede social. Eles são os responsáveis por moldar as estruturas sociais, por constituir tais redes e por manter os laços que garantem sua existência. Porém, em redes estabelecidas na internet, há um distanciamento entre os envolvidos na interação social, típico da comunicação baseada em Tecnologias da Informação e Comunicação (TIC). Nesse contexto, ainda segundo Recuero (2009), o ator passa a ser uma representação dos atores sociais ou uma construção identitária no ciberespaço (espaço das comunicações nas redes de computadores). Através das ferramentas como o Facebook, Twitter, Instagram, entre outras, os atores passam a possuir um local de fala e um espaço de interação para a construção e a narração de si (SIBILIA, 2008). Estes espaços permitem também que se perceba a construção do outro e, a partir disso, que haja interação entre esses atores. Essa interação contribui para modificações na construção desse ator virtual, sobretudo na produção de expressões e impressões acerca da "realidade" em que esses elementos estão inseridos (MARLOW, 2004).

O segundo elemento das redes sociais, as conexões, são entendidos como os laços sociais formados pelas interações entre os atores. Essas conexões na internet podem ser compreendidas em três diferentes níveis: interação, relação e laços sociais (RECUERO, 2009). De acordo com Watzlawick, Beavin e Jackson (2000), a interação é sempre um processo comunicacional, de caráter social perene e diretamente relacionado à natureza das relações entre seus envolvidos. Estudar a interação social compreende estudar a comunicação entre os atores, suas trocas de mensagens e o sentido das mesmas (COOLEY, 1975).

No contexto da comunicação mediada através das TIC, a interação pode ser síncrona, em que os envolvidos interagem na mesma hora, ou assíncrona que se refere aos envolvidos que interagem em momentos distintos (PRIMO, 2003). Ela também pode ser classificada, de 
acordo com Primo (2003), em interação mútua ou interação reativa. A interação reativa é unidirecional, ou seja, corresponde a um clique em um site, a visualizar um vídeo no YouTube, a ler um blog, entre outras interações que se baseiam em estímulo e resposta. Já a interação mútua, "é aquela caracterizada por relações interdependentes e processos de negociação, em que cada interagente participa da construção inventiva e cooperada da relação, afetando-se mutuamente" (PRIMO, 2003, p. 62). A interação mediada por TIC é sempre dialógica e no caso da interação mútua, ela sempre possuirá um impacto social, uma vez que possui reflexos nos dois lados da conexão (RECUERO, 1999).

O segundo tipo de conexão entre atores na internet é a relação social. O conjunto de interações sociais entre dois atores acaba por estabelecer um vínculo maior entre eles, que pode ser definido como sendo uma relação social (WASSERMAN; FAUST, 1994). No âmbito da internet, segundo Garton, Haythornthwaite e Wellman (1997), as relações tendem a ser mais diversificadas e há um número maior de grupos e de possibilidades de interação. Outra característica elencada por estes autores é o distanciamento presente nas relações na internet. Esse distanciamento permite o anonimato, já que a relação entre a pessoa física e a personalidade construída na internet pode não ser direta ou clara nesses ambientes. Além disso, há uma maior liberdade entre as relações uma vez que o distanciamento permite a diminuição de barreiras como sexualidade, cor, limitações físicas e geográficas. Os autores afirmam ainda que por não envolver o "eu físico" do ator, as relações mediadas por TIC podem ser mais voláteis, ou seja, facilmente se constroem e com a mesma facilidade são desfeitas.

Os laços, por sua vez, constituem uma conexão efetiva entre dois atores, resultado das relações estabelecidas entre eles. Eles são mais institucionalizados, construídos e fortalecidos no tempo por meio da interação e das relações sociais (WELLMAN, 2001). Laços consistem em uma ou mais relações específicas, tais como proximidade, contato frequente, fluxos de informação, conflito ou suporte emocional. A interconexão desses laços canaliza recursos para localizações específicas na estrutura dos sistemas sociais. Os padrões dessas relações - a estrutura da rede social - organizam os sistemas de troca, controle, dependência, cooperação e conflito (WELLMAN, 2001). O estabelecimento dos laços nas redes sociais contribui para o sentimento de pertencimento a grupos, organizações e ideias, contribuindo assim para a construção do sujeito e sua forma de interação com o meio (BREIGER, 1974).

Os atores e suas conexões (interações, relações e laços) formam uma rede social, que por sua vez terá um capital social atrelado a ela. O Capital social refere-se ao conjunto de normas de reciprocidade e confiança que acabam por emergir da conexão entre indivíduos (PUTNAM, 2000). Ainda segundo Putnam (2000), o capital social de uma rede está intimamente ligado à ideia de pertencimento a um grupo, virtude cívica e moralidade que vão se fortalecendo através das relações de um grupo. O valor social de uma rede, perpassa ainda por características individuais e coletivas. A individualidade vem dos interesses dos indivíduos em fazer parte de uma rede social para seu próprio benefício. Em seguida, destaca-se o caráter coletivo que nasce do fato de que o capital individual reflete na natureza coletiva do grupo.

\section{Metodologia}

A busca de trabalhos científicos para compor esta revisão foi realizada dentro das bases de dados Web of Science e Scopus, por se tratar de bases de dados com um amplo alcance de publicações. Além da utilização destas bases de dados, buscaram-se trabalhos nas revistas de ensino de ciências brasileiras que foram classificadas como A1 e A2 no Qualis da CAPES do ano de 2016. Dentro dessa classificação, encontram-se às revistas: Acta Scientie - Revista de Ensino de Ciências e Matemática; Alexandria - Revista de Educação em Ciências e 
Matemática; Amazônia: Revista de Educação em Ciências e Matemática; Caderno Brasileiro de Ensino de Física; Ciência \& Educação; Dynamis; Ensaio: Pesquisa em Educação em Ciências; Investigações em Ensino de Ciências; REnCiMa: Revista de Ensino de Ciências e Matemática; Revista Aretê: Revista Amazônica de Ensino de Ciências; Revista Brasileira de Ensino de Ciências e Tecnologia; Revista Brasileira de Pesquisa em Educação em Ciência e a Revista de Educação, Ciências e Matemática.

De acordo com dados oriundos das próprias redes sociais e classificados pelo portal Statista (2018), as redes sociais mais utilizadas mundialmente são, em ordem de classificação, o Facebook, o Youtube, o WhatsApp, o Facebook Messenger, o WeChat, o Instagram, o Tumblr e o Twitter. Para a construção dos termos de busca nas bases de dados, utilizou-se as redes sociais Facebook, Youtube, Instagram, Tumblr e Twitter, uma vez que as demais são voltadas para a troca de mensagens entre usuários, mesmo que WhatsApp e WeChat possuam ferramentas semelhantes ao stories do Instagram. Além dos nomes das redes sociais, fizeram parte dos termos de busca as expressões Science Teaching, Science Education e social networks. Através destes termos de busca foram obtidos 976 trabalhos apresentados na Tabela 1. Através da utilização da ferramenta Mendeley foi efetuada a comparação dos resultados das bases de dados e das revistas com o objetivo de excluir trabalhos duplicados, textos indisponíveis ou incompletos. O Mendeley é um software gratuito para organização de referências bibliográficas e análise de resultados de arquivos extraídos de bases de dados. Após esse filtro inicial, chegou-se ao número de 486 artigos compreendidos entre 2006 e 2018 . O recorte temporal não foi pré-estabelecido, este período emergiu dos resultados obtidos nas bases de dados.

Tabela 1 - Termos de busca e resultados obtidos

\begin{tabular}{|l|c|c|c|}
\hline \multicolumn{1}{|c|}{ Expressão de Busca } & $\begin{array}{c}\text { Web Of } \\
\text { Science }\end{array}$ & Scopus & $\begin{array}{c}\text { Revistas } \\
\text { Qualis A1 e A2 }\end{array}$ \\
\hline $\begin{array}{l}\text { Science teaching OR Science Education AND Facebook } \\
\text { Ensino de Ciências AND facebook }\end{array}$ & 232 & 17 & 0 \\
\hline $\begin{array}{l}\text { Science teaching OR Science Education AND Instagram } \\
\text { Ensino de Ciências AND Instagram }\end{array}$ & 16 & 0 & 0 \\
\hline $\begin{array}{l}\text { Science teaching OR Science Education AND Tumblr } \\
\text { Ensino de Ciências AND Tumblr }\end{array}$ & 6 & 1 & 4 \\
\hline $\begin{array}{l}\text { Science teaching OR Science Education AND twitter } \\
\text { Ensino de Ciências AND Twitter }\end{array}$ & 151 & 11 & 4 \\
\hline $\begin{array}{l}\text { Science teaching OR Science Education AND Youtube } \\
\text { Ensino de Ciências AND Youtube }\end{array}$ & 284 & 51 & 18 \\
\hline $\begin{array}{l}\text { Science teaching OR Science Education AND social network } \\
\text { Ensino de Ciências AND redes sociais }\end{array}$ & 849 & 96 & 31 \\
\hline
\end{tabular}

Fonte: o autor (2018).

Como o objetivo principal desta revisão era o de apontar as contribuições das redes sociais ao ensino de ciências no ensino fundamental e médio, efetuou-se a leitura dos títulos e 
resumos dos artigos encontrados e a eliminação de artigos que não se encontravam nesse quesito.

A primeira categoria eliminada, com 105 trabalhos, foi a de trabalhos que, apesar da qualidade, tratam da inserção das redes sociais no ensino de ciências no nível superior. Esses artigos trazem propostas didáticas, análises de práticas aplicadas e de metodologias de ensino aplicadas ou ligadas a cursos de graduação e, por isso, foram desconsiderados. Em seguida foram descartados da revisão os trabalhos referentes às ciências da saúde, que totalizaram 87 artigos. Havia um número considerável de artigos que tratam da utilização das redes sociais virtuais no ensino de disciplinas ligadas à medicina, psicologia, enfermagem e odontologia. A terceira categoria a não fazer parte desta revisão foi a de trabalhos relacionados à formação continuada de professores, sistematizada através das redes sociais ou da necessidade de formação para a utilização dessas ferramentas. Apesar da relevância desses 91 trabalhos, optouse pelo foco em sala de aula e o envolvimento do aluno nos trabalhos. A quarta categoria descartada foi a de trabalhos relacionados ao estudo do perfil dos professores e dos alunos que utilizam redes sociais, e demais trabalhos que buscavam descrever o comportamento dos profissionais da educação e dos alunos nas redes sociais. Esta categoria teve um total de 85 artigos. Por fim, foram descartados 93 artigos relacionados à popularização da ciência através das redes sociais virtuais e da utilização dessas redes como espaços não formais para o aprendizado científico.

As cinco categorias excluídas desta revisão compreendem um rico acervo a respeito da utilização de tecnologias da comunicação e informação no ensino de ciência, na formação de professores e na popularização da ciência e podem, futuramente, ser fruto de análises específicas. Ao final da etapa de categorização e análise de aderência à temática da revisão, restaram 25 artigos para compor a revisão.

\subsection{Categorização dos artigos selecionados}

A partir da leitura dos artigos selecionados, observou-se que eles poderiam ser categorizados através do método da análise de conteúdo (BARDIN, 2011). Através desta análise, identificou-se que eles poderiam ser separados em três categorias, sendo elas:

a) Formação de comunidades de aprendizado e aprendizado colaborativo: nessa categoria composta por quatro artigos, verificou-se o uso das redes sociais virtuais para a formação de comunidades de aprendizado ou como plataforma para a realização do aprendizado de forma colaborativa.

b) Contribuições das redes sociais virtuais para a prática docente: composta por dez artigos, essa categoria compreende exemplos de práticas didáticas, ferramentas para o ensino, pesquisas com professores e alunos, entre outros trabalhos que procuram demonstrar possíveis contribuições das redes sociais para o ensino de ciências.

c) Contribuições das redes sociais no processo de ensino e aprendizagem de ciências: nessa categoria, foram utilizados onze trabalhos que avaliaram as influências que as redes sociais causam no processo de ensino e aprendizagem e no ensino de ciências. Esses trabalhos abordam a interação entre o professor e o aluno, a alfabetização científica, as habilidades desenvolvidas com o uso da tecnologia, as possibilidades metodológicas, entre outros aspectos do ensino de ciências.

Na próxima seção, faz-se a discussão dos trabalhos analisados. 


\section{Discussão dos trabalhos analisados}

A seguir, apresentam-se uma breve análise e a discussão dos trabalhos selecionados para este estudo. Os trabalhos foram analisados nas categorias de formação de comunidades de aprendizado e aprendizado colaborativo, contribuições das redes sociais para a prática docente e contribuições das redes sociais para o processo de ensino e aprendizagem de ciências.

\subsection{Formação de comunidades de aprendizado e aprendizado colaborativo}

O primeiro trabalho analisado é de Bicen et al (2010), no qual os autores realizaram um estudo com professores da República Turca do Chipre do Norte, onde constataram que é necessária uma integração entre a sala de aula e um ambiente virtual para que uma comunidade colaborativa de construção do conhecimento seja constituída. Nesse sentido, além das aulas, o professor seria o responsável por compartilhar notas de aula e outros materiais audiovisuais sobre a temática de suas aulas para que os alunos discutam sobre esse material e contribuam com novos itens para que o aprendizado colaborativo aconteça. Os autores defendem também, que é necessária uma formação específica sobre TIC para que os professores deem conta dessas atividades.

Rolando et al. (2013), também analisou as redes sociais virtuais como uma comunidade de aprendizado. Para os autores, as comunidades virtuais de aprendizado constituem um importante espaço para que as pessoas desenvolvam a habilidade de aprender com seus pares. O compartilhamento do conhecimento, as discussões e o ambiente descontraído desses espaços contribuem para o processo de ensino e aprendizagem coletivo. Os autores destacam ainda que esses espaços acabam por contribuir para o processo de formação continuada dos professores, uma vez que eles aprendem com seus colegas de profissão e com seus alunos, têm acesso a novos materiais e ampliam o horizonte de discussões a respeito do conteúdo trabalhado. Os autores destacam ainda que há uma diferença entre somente socializar o conteúdo nesses espaços e construir aprendizado colaborativo nesses ambientes. Segundo eles, isso só ocorre quando se aumenta o nível de interação entre os participantes com um objetivo de aprendizado bem definido.

Já no trabalho de Vaz e Soares (2014), foram estudadas comunidades relacionadas a Química na rede social Orkut e como elas poderiam contribuir para o ensino de ciências de maneira colaborativa. Ao se analisar essas comunidades da rede social, Vaz e Soares (2014) constataram que elas eram formadas por participantes com afinidades em comum e que viam o conhecimento científico como forma de entretenimento; segundo os autores, essas características colaboraram com a aprendizagem informal. Os autores destacam ainda a necessidade da presença de um moderador atuante dentro de uma comunidade virtual para que objetivos relacionados ao processo de ensino e aprendizado sejam alcançados. Os autores ressaltam que os fóruns de dúvidas a respeito do conteúdo criados nesses ambientes ganham um caráter informal que abre espaço para a presença da ironia, do sarcasmo e da descontração e que isso pode levar a uma discussão infrutífera a respeito de um tema, mostrando a necessidade da atuação de um moderador. Entretanto, sua atuação não deve contribuir para encerrar o tom informal presente nesses espaços, mas sim, contribuir com a garantia do aprendizado. Os autores também consideram como positivo a integração de alunos de diferentes turmas e níveis de ensino nesses espaços, pela ampliação do debate e a possibilidade de aprendizado com seus pares, uma vez que a interação aluno-aluno, mesmo que eles sejam de diferentes níveis de ensino, aparenta ser mais efetiva que a interação professor-aluno dentro desses espaços. Por fim, os autores defendem que os professores devem criar comunidades de aprendizado dentro das redes sociais virtuais utilizadas pelos alunos com o objetivo de aliar o 
lazer ao aprendizado, mas para isso é necessário que o docente se prepare para a utilização das TIC.

Os autores Draegner, Yonezawa e Pegoraro (2017) analisaram as redes sociais sob a ótica dos fundamentos das ciências das redes com o objetivo de compreender como elas podem se tornar um espaço colaborativo para o ensino de ciências. Segundo os autores, as redes sociais virtuais podem contribuir para a criação de espaços em que a inteligência coletiva seja acessada através de questionamentos, dicas e respostas dados pelos alunos nesses ambientes. Os autores destacam ainda que é necessária, nessa rede, a presença de um agente que fomente as discussões e estimule a participação coletiva na construção do conhecimento. É favorável que esse agente seja um aluno, possibilitando assim que os estudantes sejam os responsáveis pelo seu processo de construção do conhecimento.

Por fim, concluiu-se que as redes sociais virtuais se constituem de um ambiente propício para a formação de comunidades de aprendizado colaborativo e que isso é benéfico para a popularização da ciência e para o processo de ensino e aprendizagem. Há consenso também de que o caráter informal desses ambientes contribui para a interação entre aluno e conhecimento e que é fundamental que os professores estejam preparados para atuar nesses ambientes.

\subsection{Contribuições das redes sociais para a prática docente}

Em 2008, Costa et al. (2009) apresentaram uma proposta de criação de um diário de conteúdos utilizando o Twitter. A ideia do trabalho realizado foi a de verificar o funcionamento do micro blog como um repositório de insights, questionamentos e destaques a respeito do conteúdo trabalhado. O estudo não foi frutífero na época devido ao desconhecimento do que era o Twitter por grande parte dos participantes, pois em 2008, esta rede social ainda era desconhecida.

Em 2010, segundo Zhang et al. (2010), já era possível verificar uma disseminação maior das redes sociais e dos dispositivos móveis, assim como um aumento da pesquisa relacionada a essas tecnologias como facilitadoras da prática docente. Estes autores acompanharam as possibilidades de contribuição da utilização de tecnologias móveis no ensino de ciências em uma escola de Singapura. Segundo os autores, a utilização de dispositivos móveis em sala de aula contribui para que os estudantes acessem comunidades de suporte e de recursos disponíveis na internet, fazendo com que qualquer assunto possa ser contextualizado e explorado durante uma aula. O uso de dispositivos móveis aliado ao acesso às redes sociais durante a aula, segundo os autores, contribui para a construção do conhecimento de maneira colaborativa. Além de acessarem conteúdo nesses espaços, a possibilidade de compartilhar vídeos, fotos, desenhos e outros materiais audiovisuais contribui para a interação entre os alunos e aumenta o engajamento dos estudantes nas atividades. Os autores finalizam que a utilização das redes sociais e dos dispositivos móveis nas aulas de ciências contribuem para um ensino baseado em investigação e reforçam que o papel do professor e o formato das aulas precisam ser desconstruídos para que se possa obter o êxito desejado com esses recursos. O trabalho de Zhang et al (2010) vai além da contribuição das redes sociais e sua leitura é recomendada para aqueles que desejam desconstruir e reconstruir atividades para o ensino de ciências que sejam baseadas em dispositivos móveis.

Christine Greenhow (2011) conduziu um estudo para explorar as relações existentes entre as redes sociais Facebook e MySpace e o aprendizado. Segundo a autora, na época da pesquisa, as redes sociais dividiam profissionais da educação entre aqueles que as defendiam e aqueles que as consideravam como uma distração no ambiente escolar. De acordo com 
Greenhow (2011), esses ambientes servem como uma válvula de escape para o estresse relacionado à escola. Além disso, a informalidade que permeia esses espaços contribui para que os estudantes aprendam com seus pares e desenvolvam sua criatividade através de atividades que explorem esses ambientes. Greenhow (2011) finaliza afirmando que sites como o MySpace e o Facebook contribuem para a criação de atividades investigativas, que exijam argumentação e que tirem o aluno da posição passiva no processo de aprendizagem.

A mudança da postura do aluno de uma posição passiva para uma posição ativa no processo de ensino e aprendizagem também é abordada no trabalho de İşman e Ucun (2012). Em seus estudos, realizados na Turquia, os pesquisadores identificaram que a presença maciça dos alunos no Facebook se deve à conexão dos indivíduos a seus gostos pessoais. Nesse contexto, os autores sugerem que ao invés do professor criar conteúdo para essas plataformas, é interessante que ele motive seus alunos a desenvolverem conteúdo para essas plataformas, aproximando assim o conhecimento científico das afinidades pessoais de cada estudante.

Alguns pesquisadores buscaram também verificar a eficiência dos métodos baseados em atividades audiovisuais comparadas ao modelo tradicional de ensino. Day et al (2012) conduziu um estudo no nono ano de uma escola de Woodbridge nos Estados Unidos, no qual utilizou vídeos disponíveis no YouTube para a contextualização e organização do conhecimento com os alunos a respeito de tópicos ligados às ciências dos materiais. Em seguida, os alunos desenvolveram seus próprios vídeos a respeito da temática para essas redes. Segundo os pesquisadores, a utilização dos vídeos disponíveis na internet contribuiu com a mesma eficiência que os materiais tradicionais utilizados em sala de aula para o processo de ensino e aprendizagem. Os autores ressaltam ainda a necessidade de dar ao professor tempo de planejamento para a seleção dos materiais em redes como o Youtube, sobretudo para a garantia do material que será utilizado.

Em 2013, foi publicado o trabalho de Yoon, Lee e Lee da Coreia do Sul em que se destaca a interação com os estudantes nativos digitais. Os autores analisaram a interação professor-aluno sob a ótica da interação entre nativos digitais (alunos) com os imigrantes digitais (professores). Segundo Yoon et al (2013), é necessário que os professores desconstruam sua imagem e maneira de trabalho, que em muito carregam as características dos professores que eles tiveram durante a sua formação num contexto baseado em papel. Além disso, os autores apontam a necessidade da formação dos professores para o trabalho através das mídias interativas. Por fim, considera-se importante a ampliação do tempo de contato com o conteúdo que as redes sociais possibilitam, uma vez que o contato online vai além do tempo ocorrido em sala de aula.

As contribuições que as redes sociais podem trazer ao ensino de ciências também foram investigadas por Vivitsou et al (2016). Os pesquisadores entrevistaram professores da Finlândia e da Grécia para compreender tais contribuições. Segundo os autores, o contato com os colegas nesses ambientes aumenta a possibilidade de aprendizado dos alunos. As redes sociais e o contato com os dispositivos móveis também contribuem para que os alunos estabeleçam relações entre a ciência e a tecnologia e a ciência e a sociedade. Os autores também afirmam que, além do professor incentivar a troca de informações entre os alunos nas redes sociais, deve haver troca e compartilhamento entre os professores nesses espaços para enriquecer a prática docente.

Outra contribuição para o desenvolvimento dos alunos é detalhada no trabalho de Lee et al (2016). Os autores utilizaram redes sociais para desenvolver habilidades de resolução de problemas, resolução de problemas de forma colaborativa e comunicação entre os pares com alunos do ensino fundamental de uma escola da Coreia do Sul. A sequência didática proposta 
tratava da prevenção do aquecimento global e contou com as etapas de preparação, apresentação do problema, planejamento das soluções, resolução dos problemas, elaboração de relatório e apresentação e avaliação final. A busca de informações e a produção do trabalho foi realizada através das redes sociais e de ferramentas de produção colaborativa como o Google Docs. Os autores concluíram que a prática aumentou o engajamento dos alunos em sala de aula e, consequentemente, aumentou a frustração dos alunos ao enfrentarem obstáculos como a limitação da internet em sala de aula. A sequência didática se mostrou positiva para o desenvolvimento das habilidades de resolução de problemas e de trabalho em equipe.

As redes sociais, segundo Luo e Dani (2016), também podem contribuir para a aplicação e a disseminação de metodologias interativas, como o Peer Instruction ou Instrução entre pares. O Twitter é apresentado como ferramenta para o desenvolvimento de atividades educacionais baseadas na metodologia do peer instruction. De acordo com os autores, o ambiente e as funcionalidades do Twitter permitiram que o professor desenvolvesse a metodologia com facilidade (LUO, T; DANI, D., 2016).

O trabalho de Bedin (2017) defende que o professor deve auxiliar no processo de transformação da realidade em que está inserido, portanto, como as redes sociais passaram a fazer parte do cotidiano das pessoas, o professor deve estar inserido nelas. $\mathrm{O}$ autor sugere a promoção de projetos de aprendizagem de caráter interdisciplinar nos quais os alunos podem desenvolver suas atividades dentro das redes sociais, promovendo assim, a interação professoraluno nos ambientes virtuais e a digitalização da prática docente.

Após a análise destes trabalhos, conclui-se que as redes sociais contribuem para a prática docente por apoiar o aprendizado colaborativo, incentivar o aprendizado informal, ampliar o contato com o conteúdo para além da sala de aula, enriquecer as atividades propostas e aplicar metodologias de ensino já conhecidas pela sua efetividade em sala de aula.

\subsection{Contribuições das redes sociais para o processo de ensino e aprendizagem de ciências}

O trabalho de Costa e Ferreira (2012) efetuou um estudo que buscou compreender o papel do professor diante das novas possibilidades metodológicas trazidas pelas redes sociais e como essas novas formas de interação podem impactar no processo de ensino e aprendizagem. Segundo os autores, a dinâmica professor-aluno pode sofrer fortes alterações sobretudo pelo contato fora da sala de aula e pelo desafio de canalizar o entusiasmo dos usuários das redes sociais para o ensino. Costa e Ferreira (2012) afirmam ainda que as redes sociais podem ser vistas como um oceano de informações e conhecimento e que um dos novos papéis dos professores é auxiliar os alunos a adquirirem a habilidade de julgar essas informações, identificar sua veracidade e como ela pode contribuir para a transformação do cotidiano. Outra característica das redes sociais é a possibilidade da antecipação dos conteúdos que serão trabalhados em sala de aula, assim como seu aprofundamento após a aula. Os autores salientam ainda o caráter colaborativo e cooperativo na construção do conhecimento e a criação de arquiteturas pedagógicas dentro das redes sociais, que seriam:

estruturas de aprendizagem realizadas a partir da confluência de diferentes componentes: abordagem pedagógica, software educacional, internet, inteligência artificial, Educação a Distância, concepção de tempo e espaço. O caráter dessas arquiteturas pedagógicas é pensar a aprendizagem como um trabalho artesanal, construído na vivência de experiências e na demanda de ação, interação e metareflexão do sujeito sobre os fatos, os objetos e o meio ambiente socioecológico (KERCKHOVE, 2003). Seus pressupostos curriculares compreendem pedagogias 
abertas capazes de acolher didáticas flexíveis, maleáveis, adaptáveis a diferentes enfoques temáticos (CARVALHO; NEVADO; MENEZES, 2007 apud COSTA; FERREIRA, 2012).

Noh et al. (2013) publicaram um estudo que aplicou a metodologia Delphi para a busca de um consenso entre especialistas da área de educação e tecnologia da Malásia sobre os impactos e o uso do Facebook na educação. Segundo os autores, atividades como feedback sobre a produção dos alunos podem ser transferidas para essas plataformas, assim como a distribuição de material, leitura prévia e demais atividades que possam ser retiradas da sala de aula, com o objetivo de melhorar o aproveitamento do tempo professor-aluno, que é extremamente reduzido. Noh et al. (2013) destacam também a importância do desenvolvimento de habilidades como comunicação no ciberespaço, interação com mídias sociais e alfabetização digital que são fundamentais para o mercado de trabalho atual.

Wang et al. (2014) trabalharam com professores de ciências das escolas de Nova Iorque com o objetivo de inserir as TICs na prática docente. De acordo com os autores, a prática docente deve se orientar por metodologias construtivistas e centradas no aluno e, nesse contexto, as redes sociais podem ser grandes aliadas dos professores. Wang et al. (2014) destacam que é necessário se portar de maneira diferente diante dessas tecnologias: enquanto os livros e alguns materiais audiovisuais utilizados possuem uma abordagem passiva, as redes sociais necessitam de uma postura ativa na produção e manuseio do conteúdo. Nesse contexto, entende-se que as habilidades cognitivas de exploração, análise, inferência e avaliação científica utilizadas na construção do conhecimento podem contar com a tecnologia como uma ferramenta de apoio do seu desenvolvimento. Entender que essas tecnologias não são somente entretenimento e que elas mudam a forma de aprender, trabalhar e se relacionar é fundamental para os docentes da atualidade (WANG et al., 2014).

Pedro, Passos e Arruda (2015) afirmam, em seu trabalho a respeito da aprendizagem científica no Facebook, que o processo de ensino e aprendizagem pode ser enriquecido através da participação social numa comunidade. Essa participação, segundo eles, constrói identidades, envolve os estudantes em práticas significativas e amplia os horizontes para além das práticas ocorridas em sala de aula. Por isso, a utilização das redes sociais como espaço colaborativo para a construção do conhecimento se torna necessário atualmente (PEDRO et al., 2015).

Leite e Leão (2015) analisaram as contribuições da web 2.0 para a aprendizagem. Destaca-se o entendimento de aprendizagem 2.0 apresentado pelos autores, uma vez que através das redes sociais é possível construir um processo de ensino e aprendizagem baseado na interação entre os pares, a experimentação, a reflexão e a geração de conhecimentos individuais e coletivos. Os autores ainda chamam a atenção para a necessidade da utilização de tais ferramentas aliadas ao uso de metodologias de ensino e teorias de ensino e aprendizagem, sugerindo para tal a teoria da flexibilidade cognitiva como método de ensino e a teoria dos construtos sociais como teoria de ensino e aprendizagem.

Alabdulkareem (2015) realizou um estudo com alunos e professores do ensino fundamental da Arábia Saudita. Em seu trabalho, o autor ressalta os pontos já levantados nesta revisão a respeito das contribuições para o processo de ensino e aprendizagem. $\mathrm{O}$ autor apresenta ainda que mais de $70 \%$ dos alunos e $100 \%$ dos professores observados/analisados possuem dispositivos que acessam as redes e que professores e alunos acreditam que essas tecnologias podem contribuir para o aprendizado, porém, seu uso em sala de aula não é observado nas escolas estudadas por Alabdulkareem (2015). Segundo o autor, é necessário que sejam estabelecidos programas de formação continuada de conteúdos referentes à utilização das mídias sociais no contexto escolar. Estes conteúdos também devem estar presentes na formação dos futuros professores. 
Schwarz e Caduri (2016) efetuaram trabalhos em Israel a respeito da utilização das redes sociais em sala de aula liderada pelos professores. Segundo os autores, as redes sociais estão implicando em alterações psicológicas, éticas e pedagógicas dentro do ambiente escolar e que, por isso, elas vêm ganhando o interesse dos pesquisadores. Para o estudo, foi aplicada a metodologia da pesquisa narrativa sobre o trabalho de professores considerados destaque na utilização de redes sociais em sala de aula. O trabalho de Schwarz e Caduri (2016) resultou em quatro categorias de impacto no processo de ensino e aprendizagem trazidas pelas redes sociais. O primeiro deles é o do aprendizado social. Segundo os autores, através das redes sociais, é possível criar um ambiente de aprendizado social em que é possível discutir métodos de pesquisa, promover críticas aos pares, fazer perguntas, interagir com diferentes situações e formular hipóteses, entre outros aspectos característicos da aprendizagem de maneira coletiva. O segundo aspecto é o da autonomia. Nesse sentido, Schwarz e Caduri (2016) destacam a importância da autonomia dos alunos no processo de criação e compartilhamento do conteúdo, apesar do ambiente cooperativo e colaborativo trazido pelas redes sociais, a autonomia e a individualidade presente nos perfis pessoais dos estudantes contribui para o engajamento nas atividades e a melhoria das habilidades de comunicação e negociação dos alunos. O terceiro aspecto destacado pelos autores é o engajamento ativo dos estudantes nas atividades, já mencionado por outros autores que compuseram essa revisão. Por fim, o quarto aspecto é o de "aprender a fazer parte de uma comunidade de aprendizes". Nesse sentido, os autores destacam a importância desses alunos aprenderem a fazer parte de uma comunidade que constrói o conhecimento de maneira coletiva, de entenderem que além de serem responsáveis pelo seu próprio aprendizado eles também eram responsáveis pelo aprendizado de seus pares. Além disso, através de uma comunidade de aprendizado, cria-se a possibilidade de criar identificação com um conteúdo muitas vezes distante da realidade em que os alunos estão inseridos (SCHWARZ; CADURI, 2016).

Giassi e Ramos (2016) acompanharam trabalhos envolvendo a produção de vídeos e utilização do YouTube numa escola em Santa Catarina. Segundo as autoras, a principal contribuição ao processo de ensino e aprendizagem trazido por essas tecnologias é a empatia que os estudantes têm por elas. Além disso, elas reforçam a necessidade da transformação da informação presente nesses espaços de conhecimento e que este é um dos grandes desafios da prática docente na atualidade.

Akgunduz e Akinoglu (2016) efetuaram um estudo com alunos e professores do Ensino Fundamental em Istambul com o objetivo de estudar os impactos do ensino híbrido (sala de aula tradicional e atividades na internet) no ensino de ciências. O estudo foi efetuado com um grupo controle (ensino tradicional) e um grupo que recebeu aulas em ensino híbrido para efeitos de comparação. Os autores não notaram grandes diferenças em termos do número de acertos entre os grupos, porém entre os estudantes que efetuaram atividades híbridas, notou-se uma melhoria das habilidades relacionadas ao estudo autodirigido.

Silva, Perreira e Arroio (2017) estudaram a relação entre o YouTube e o estudo de Química, Física e Biologia entre estudantes de Ensino Médio do Rio de Janeiro. Na investigação realizada, os autores constataram que a busca de vídeos no YouTube pelos alunos se dá pela não identificação com um determinado tipo de aula, porém, ao se investigar os vídeos assistidos observou-se que eles seriam uma reprodução da aula tradicional. Por isso, os autores afirmam que há elementos além da não identificação com o professor, como a possibilidade de rever o conteúdo várias vezes ou estudar para uma avaliação. Os autores ainda afirmam que, mesmo que ignorada por alguns professores, a presença do conteúdo disponibilizado nas redes sociais faz parte do processo de ensino e aprendizagem dos atuais estudantes. 
Pecay (2017) observou professores filipinos nos métodos da fenomenologia para entender o impacto do YouTube no processo de ensino e aprendizagem. Nesse sentido, os professores podem se beneficiar da produção de conteúdo seguido do seu compartilhamento ou da seleção de material presente nesta plataforma. Segundo os autores, a diferença entre a utilização da plataforma está ligada às habilidades do professor em relação a conteúdos digitais e audiovisuais. $\mathrm{O}$ autor reforça ainda que essas redes podem contribuir para o fortalecimento e/ou a disseminação de concepções científicas equivocadas e que o professor precisa estar preparado para trabalhar com essa situação. Pecay (2017) também afirma que o uso do vídeo em sala de aula pode contribuir para um aprendizado significativo, uma vez que proporciona o desenvolvimento de habilidades de comunicação, pensamento crítico, conhecimento a respeito do conteúdo e aprender a aprender. A visualização de modelos e situações também contribui para o aumento da compreensão do conteúdo por parte dos estudantes. O autor também afirma que os benefícios trazidos pelo uso do YouTube em sala de aula podem ser comprometidos pela falta de tempo que os professores possuem para fazer uma seleção criteriosa do material que será utilizado. Em sua conclusão, Pecay (2017) afirma que os professores muitas vezes não exploram ferramentas como o YouTube por carregarem consigo a ideia de que essas tecnologias irão substituir o docente, porém, ele reforça que o uso adequado das mesmas em sala de aula pelo professor garante e reforça a presença desse profissional dentro do processo de ensino e aprendizagem.

A análise desses artigos confirma a percepção natural de que a tecnologia vem mudando não só a nossa maneira de nos comunicarmos e trabalharmos, mas também a nossa forma de aprender e ensinar. É comum aos trabalhos selecionados a percepção de que o caráter colaborativo das redes sociais enriquece o processo de ensino e aprendizagem, bem como se compreende que novas habilidades precisarão ser desenvolvidas por professores e alunos para a boa utilização das tecnologias de informação e comunicação. Por fim, consideramos que um dos maiores desafios é o de criar a habilidade nos alunos de saber selecionar no oceano de informações presentes nas redes sociais o que pode se tornar conhecimento.

\section{Considerações finais sobre a revisão de literatura}

A revisão de literatura a respeito das contribuições das redes sociais no ensino de ciências apresentou uma riqueza de trabalhos oriundos de quatro continentes do globo. Apesar da diversidade dos artigos encontrados, pode-se afirmar que há uma convergência com relação ao aprendizado cooperativo, ao engajamento dos alunos, à necessidade da formação de professores frente às ferramentas audiovisuais e o desenvolvimento de novas habilidades e competências necessárias para a vida nos tempos atuais.

As características da informalidade presente nesses espaços e a promoção da conexão e a criação de laços entre seus participantes cria um ambiente propício para a interação entre aluno, professor e conteúdo. Essa interação favorece o aprendizado e contribui para o engajamento e motivação dos estudantes que atuam de maneira cooperativa e colaborativa nestes ambientes. A presença dos conteúdos de ciências nestes espaços é benéfica também para a popularização da ciência, uma vez que seu alcance vai além da comunidade escolar.

Outra contribuição das redes sociais para a prática pedagógica de ciências é a possibilidade de ampliar o espaço-tempo da sala de aula. O contato com o conteúdo para além do tempo escolar favorece a aprendizagem e amplia as possibilidades metodológicas do professor. 
A necessidade da formação continuada dos professores para a atuação nestes espaços também se faz necessária, uma vez que, além dos conhecimentos tecnológicos, se faz necessário um reposicionamento do papel do professor e da relação docente-discente nestes espaços. $\mathrm{O}$ desenvolvimento do pensamento crítico dos estudantes em atividades que propiciem a análise de informações presentes nesses espaços é outro aspecto positivo da utilização das redes sociais.

Por fim, destaca-se que a convergência dos artigos em três grandes categorias pode resultar na criação de linhas de pesquisa e de ação docente, promovendo assim a criação do conhecimento e a análise dos resultados das práticas que já ocorrem nestes espaços virtuais. Como possibilidades de trabalhos futuros, sugere-se ainda, a ampliação dos estudos a respeito das metodologias de ensino utilizadas nestes ambientes, bem como as concepções de ensino e aprendizagem dos professores que utilizam estes espaços em suas práticas pedagógicas.

\section{Referências}

AKGUNDUZ, D.; AKINOGLU, O. The Effect of Blended Learning and Social MediaSupported Learning on the Students' Attitude and Self-Directed Learning Skills in Science Education. Turkish Online Journal of Educational Technology (TOJET), v. 15, n. 2, p. 106-115, 2016.

ALABDULKAREEM, S. A. Exploring the use and the impacts of social media on teaching and learning science in Saudi. Procedia-Social and Behavioral Sciences, v. 182, p. 213-224, 2015.

ARROIO, A.; GIORDAN, M. O vídeo educativo: aspectos da organização do ensino. Química nova na escola, v. 24, n. 1, p. 8-11, 2006.

BARDIN, L. Content analysis. São Paulo: Edições, v. 70, 2011.

BEDIN, E. Aprendizagem Colaborativa, Troca de Saberes e Redes Sociais: tríade na Educação Básica. Revista Brasileira de Ensino de Ciência e Tecnologia, v. 10, n. 2, 2017.

BICEN, H.; CAVUS, N. The most preferred social network sites by students. ProcediaSocial and Behavioral Sciences, v. 2, n. 2, p. 5864-5869, 2010.

BOYD, D. M.; ELLISON, N. B. Social network sites: Definition, history, and scholarship. Journal of Computer-Mediated Communication, v. 13, n. 1, 2007.

BREIGER, R. L. The duality of persons and groups. Social forces, v. 53, n. 2, p. 181-190, 1974.

BROWN, A.L. Metacognitive development and reading. Em R.J. Spiro, B.C. Bruce \& W. F. Brewer (org.). Theoritical issues in reading comprehension. Hillsdade: Lawrence Erlbaum Associates. 1980.

BROWN, A.L. Transforming schools into communuties of thinking and learning about serious matters. American Psychologis, v. 52, n. 4. 1997.

CASTELLS, M. Network theory: A network theory of power. International Journal of Communication, v. 5, p. 15, 2011. 
CHAGAS, I. Utilização da Internet na aprendizagem da Ciência. Que caminhos seguir. Lisboa, v. 14, p. 13-26, 2001. Disponível em:

http://www.educ.fc.ul.pt/docentes/ichagas/index.html/Utilizacao\%20educativa\%20da\%20Inte rnetINOVACAO.pdf. Acesso em: 12 nov. 2014.

COOLEY, C.H. Social Organization. New York: Schocken Books, 1909, republished 1975.

COSTA, A. M. S. N.; FERREIRA, A. L. A. Novas possibilidades metodológicas para o ensino-aprendizagem mediados pelas redes sociais Twitter e Facebook. Revista de Ensino de Ciências e Matemática, v. 3, n. 2, p. 136-147, 2012.

COSTA, et al. How people are using Twitter during conferences. Creativity and Innovation Competencies on the Web. Proceedings of the 5th EduMedia, p. 145-156, 2009.

DEGENNE, Alain; FORSÉ, Michel. Introducing social networks. Sage, 1999.

DRAEGER, D. I; YONEZAWA, W. M.; PEGORARO, R. Fundamentos da ciência das redes presentes nas redes sociais virtuais como instrumento de ensino de biologia. Revista Brasileira de Ensino de Ciência e Tecnologia, v. 9, n. 3, 2017.

FREIRE, P. Pedagogia da autonomia: saberes necessários à prática docente. São Paulo: Paz e Terra, 1996.

GALEMBECK, E. Aprendizagem Colaborativa à distância. 2003. Disponível em: http://www.ead.unicamp.br/eventos/evento.html. Acesso em: 10 set. 2018.

GARTON, L.; HAYTHORNTHWAITE, C. E WELLMAN, B. Studying online - Social Networks. Journal of computer mediated communication, n. 3, v 1,1997.

GIASSI, M. G.; RAMOS, M. C. Tecnologias da informação e comunicação no ensino aprendizagem de ciências. Revista Dynamis, v. 22, n. 2, p. 52-62, 2016.

GREENHOW, C. Online social networks and learning. On the Horizon, 2011.

ISMAN, A.; UCUN, K. Objectives of the students use general and vocational education students to Facebook. Procedia-Social and Behavioral Sciences, v. 55, p. 1-10, 2012.

JUNCO, R. The relationship between frequency of Facebook use, participation in Facebook activities, and student engagement. Computers \& Education, n 58, v1. 2012.

KERCKHOVE, D. Inteligências en conexión: hacia una sociedad de la web. Madrid, Espanha. GEDISA, 1997. P. 104.

KENSKI, V. M. Aprendizagem mediada pela tecnologia. Revista diálogo educacional, v. 4, N.10, 2003, P.47-56.

LEE, J. et al. Enhancing problem solving skills in science education with social media and an e-collaboration tool. The New Educational Review, v. 1, n. 43, p. 248, 2016.

LEITE, B. S.; LEÃO, M. B. C. Contribuição da Web 2.0 como ferramenta de aprendizagem: um estudo de caso. Revista brasileira de ensino de ciência e tecnologia, v. 8, n. 4, 2015. 
LÉVY, P. A inteligência coletiva: por uma antropologia do ciberespaço. São Paulo, SP. Loyola, 1998.

LUO, T.; DANI, D. E.; CHENG, L. Viability of using Twitter to support peer instruction in teacher education. International Journal of Social Media and Interactive Learning Environments, v. 4, n. 4, p. 287-304, 2016.

MARLOW, Cameron. Audience, structure and authority in the weblog community. In: International Communication Association Conference. 2004.

MARTINS, A. M. Autonomia e educação: a trajetória de um conceito. Cadernos de pesquisa, n. 115, p. 207-232, 2002.

MEADOWS, A. J. A comunicação científica. Brasília: Briquet de Lemos, 1999. 268 p.

MORAN, J. M. Ensino e Aprendizagem inovadores com apoio de tecnologias. In: MORAN. J. M; MASETTO, M. T.; BEHRENS, M. A. Novas Tecnologias e Mediação Pedagógica. Campinas, SP: PAPIRUS, 2013.

NOH, N. M. et al. Usage of Facebook: The future impact of curriculum implementation on students in Malaysia. Procedia-Social and Behavioral Sciences, v. 103, p. 1261-1270, 2013.

PECAY, R. K. D. YouTube Integration in Science Classes: Understanding Its Roots, Ways and Selection Criteria. Qualitative Report, v. 22, n. 4, 2017.

PEDRO, C. L.; PASSOS, M.M.; ARRUDA, S. M. Aprendizagem científica no facebook. Alexandria: Revista de Educação em Ciência e Tecnologia, v. 8, n. 1, p. 3-19, 2015 .

PRIMO, A. F. T. Interação mediada por computador. 2003. Tese de Doutorado. Universidade Federal do Rio Grande Do Sul. Porto Alegre: UFRGS, 2003.

PUTNAM, R. D. Bowling alone: America's declining social capital. In: PUTNAM, R.

D. Culture and politics. Palgrave Macmillan, New York, 2000. p. 223-234.

RADFAHRER, L. Design/Web/Design. São Paulo, SP: Market, 1998.

RECUERO, R. A Conversação em Rede: A Comunicação Mediada pelo Computador e as Redes Sociais na Internet. Porto Alegre: Sulina, 2012.

ROLANDO, L. G. R.; SALVADOR, D. F.; LUZ, M. R.M.P. The use of internet tools for teaching and learning by in-service biology teachers: A survey in Brazil. Teaching and Teacher Education, v. 34, p. 46-55, 2013.

SANTOS, M. L. B; ATANAZIO, A. M. C.; FRANÇA, H. S.; PARANHOS, M.; LEÃO, M. B. C.; LEITE, A. E. As Tecnologias de Informação e Comunicação no Ensino de Ciências: entrevista com o professor Marcelo Brito Carneiro Leão. ACTIO, Curitiba, v. 3, n. 3, p. 214235, set./dez. 2018.

SIBILIA, P. O show do eu: a intimidade como espetáculo. Rio de Janeiro: Nova Fronteira, 2008. 
SILVA, M. J.; PEREIRA, M.V.; ARROIO, A. O papel do youtube no ensino de ciências para estudantes do ensino médio. Revista de Educação, Ciências e Matemática, v. 7, n. 2, 2017.

SCHWARTZMAN, S. A ciência da ciência. Ciência Hoje, v. 2, n. 11, p. 54-9, 1984.

SCHWARZ, B.; CADURI, G. Novelties in the use of social networks by leading teachers in their classes. Computers \& Education, v. 102, p. 35-51, 2016.

STATISTA. Most famous social network sites worldwide as of April 2018, ranked by number of active users. Disponível em:

https://www.statista.com/statistics/272014/globalsocial-networks-ranked-by-number-ofusers/. Acesso em: 27 jun. 2018.

VAZ, W. F.; SOARES, M. H. F. B. Análise de comunidades de Química da Rede Social Orkut: comunicação, conceito e linguagem no Ensino de Química. Revista Brasileira de Pesquisa em Educação em Ciências, v. 14, n. 1, p. 101-123, 2014.

VIVITSOU, M. et al. Student-driven knowledge creation through digital storytelling. New Ways to Teach and Learn in China and Finland: Crossing boundaries with technology, p. 35-54, 2016.

WANG, S.K. et al. Professional development to enhance teachers' practices in using information and communication technologies (ICTs) as cognitive tools: Lessons learned from a design-based research study. Computers \& Education, v. 79, p. 101-115, 2014.

WASSERMAN, S.; FAUST, K. Social Network Analysis. Methods and Applications. Cambridge, UK: Cambridge University Press, 1994.

WATZLAWICK, P.; BEAVIN, J. H.; JACKSON, D. D. Menschliche Kommunikation: Formen, Störungen, Paradoxien, 10. Aufl. Bern: Huber, 2000.

WELLMAN, B. The rise (and possible fall) of networked individualism. Connections, v. 24, n. 3, p. 30-32, 2002.

YOON, S. Y.; LEE, J.; LEE, C. H. Interacting with screenagers in classrooms. ProcediaSocial and Behavioral Sciences, v. 103, n. 1, p. 534-541, 2013.

ZHANG, W. et al. The revolution will be networked: The influence of social networking sites on political attitudes and behavior. Social Science Computer Review, v. 28, n. 1, p. 75-92, 2010.

Recebido em abril de 2020.

Aprovado em novembro de 2020. 